\title{
AC 2007-1145: THE WOMEN IN SCIENCE AND ENGINEERING (WISE) PROGRAM AT THE UNIVERSITY OF SOUTHERN CALIFORNIA: ACHIEVEMENTS AND CHALLENGES OF THE FIRST FIVE YEARS
}

\section{Nicole Hawkes, WiSE / University of Southern California}

Nicole Hawkes is the Program Manager for the Women in Science and Engineering (WiSE) Program at the University of Southern California. She received a B.A. in History from Mount Holyoke College in 1996, an M.A. in African Studies from the University of Illinois at Urbana-Champaign in 2000, and an M.S. in Arts Administration from Boston University in 2002.

\section{Jean Morrison, University of Southern California}

Jean Morrison is the Vice Provost for Graduate Programs at the University of Southern California and a Professor in the Department of Earth Sciences. Since 2002, she has been the Director of the USC Women in Science and Engineering (WiSE) program. She received her Ph.D. from the University of Wisconsin, Madison, in 1988; her M.S. from the University of Georgia in 1983; and her B.A. from Colgate University in 1980.

\section{Cauligi Raghavendra, University of Southern California}

Cauligi Raghavendra is the Senior Associate Dean for Strategic Initiatives at the USC Viterbi School of Engineering. He is a Professor in the Departments of Electrical Engineering-Systems and Computer Science at the University of Southern California. He received his B.Sc (Hons) Physics degree from Bangalore University in 1973, his B.E and M.E degrees in Electronics and Communications from Indian Institute of Science, Bangalore in 1976 and 1978 respectively. He received his Ph.D degree in Computer Science from University of California at Los Angeles in 1982. 


\title{
The Women in Science and Engineering (WiSE) Program at the University of Southern California: Achievements and Challenges of the First Five Years
}

\begin{abstract}
The establishment of the Women in Science and Engineering (WiSE) Program represents the serious commitment of the University of Southern California to address the under-representation of women in science and engineering. Since the launch of the program in 2000, WiSE has helped to more than double the number of tenured and tenure-track women faculty at USC from 15 to 35 , through its recruitment and retention programs. Its complimentary programs to support undergraduates, graduate students, and postdoctoral scholars through a range of financial awards and activities have also grown in scope and impact. This paper describes the programs developed and administered by WiSE, the perceived successes to date, the challenges that remain, and the future directions of the program to ensure continued progress toward gender equity in science and engineering at USC. Through an analysis of the WiSE Program at USC, we hope to present a model from which others can draw on to tackle the same issues at their own institutions.
\end{abstract}

Introduction

In 2000, the University of Southern California (USC) launched its Women in Science and Engineering (WiSE) Program. Funded by a \$20 million gift to the endowment, the goal of the program is to increase the number of tenured and tenure-track women faculty in science and engineering (S\&E). Spearheaded by an energetic group of tenured faculty, the programs and activities of the WiSE program have been designed to address a broad range of issues that affect the representation of women in $\mathrm{S} \& \mathrm{E}$.

Operating from the Office of the Provost, WiSE works with deans and departments in the USC College of Letters, Arts, and Sciences and the USC Viterbi School of Engineering to recruit outstanding women scientists and engineers to the university and to retain those who might be tempted to move elsewhere. In the 5 years since the program's inception, WiSE resources have helped the schools to more than double the number of tenured and tenure-track (T/TT) women faculty in S\&E fields from 15 to 35.

In addition to its primary goal of faculty gender diversity, WiSE has developed a series of programs to address pathway (pipeline) and institutional climate issues that remain obstacles to attracting and retaining women in the fields of S\&E. While WiSE programs provide targeted financial support to scholars at all stages of their careers, the resources are heavily focused on support of doctoral students, with the intent to prepare the next generation of S\&E faculty.

Though similar initiatives to increase the representation of women in S\&E are in place at academic institutions across the country, largely funded by the National Science Foundation ADVANCE Program, USC's WiSE program is unique because of its permanent endowment and its comprehensive program design. In its recent issue focused on campus diversity, the 
Chronicle of Higher Education featured the USC WiSE Program as a model initiative for increasing the number of women in S\&E fields and supporting their professional development:

The program's breadth and substantial resources set it apart, say those familiar with similar programs at other institutions. "It is a great program," says Donna J. Nelson, associate professor of chemistry at the University of Oklahoma, who has studied the role of women faculty members in the sciences and engineering at research universities. "WISE is doing the right thing by spreading resources among all levels."

Operating on roughly the same timeline as recipients of NSF ADVANCE Institutional Transformation grants, the first of which were awarded in 2001, WiSE has benefited from lessons learned at NSF ADVANCE institutions as well as by developing new strategies. By looking carefully at other successful approaches for solving the problem of women's underrepresentation in $\mathrm{S} \& \mathrm{E}$ and adapting them to the particular culture and challenges confronting USC, WiSE was able to model elements of its programs on those strategies and combine them into a comprehensive series of programs with room for growth and expansion.

Even though USC still ranks below the national average, particularly in the physical sciences and engineering, significant advances have been made in increasing the number of T/TT women faculty in S\&E. An evaluation of WiSE's successes must be balanced with a critical examination of its progress compared nationally to its peer institutions, and relative to USC's gender diversity in S\&E prior to the inception of the WiSE Program.

USC: Pre-WiSE and Today

The USC Viterbi School of Engineering is among the top engineering programs in the United States. Consistently in the top ten in the U.S. News and World Report rankings of graduate programs, in 2006 USC's Viterbi School ranked number nine. With over \$150 million in external funding support, the school is among the nation's highest in volume of research activity per faculty. In 2000, the Viterbi School was lacking in faculty gender diversity: 3 women T/TT faculty spanned the 8 departments of the Viterbi School of Engineering, constituting $2 \%$ of the $148 \mathrm{~T} / \mathrm{TT}$ faculty.

Since the inception of WiSE, and in a span of 6 years, the number of women T/TT faculty in Viterbi has quadrupled to 12. The 9 women faculty members hired in the Viterbi School in that period are distributed rather evenly over 6 departments: 3 in Computer Science, 2 in Industrial and Systems Engineering, and 1 each in Electrical, Biomedical, Civil and Environmental, and Aerospace and Mechanical Engineering. Women faculty now represent $7 \%$ of the $170 \mathrm{~T} / \mathrm{TT}$ engineering faculty, which is just below the national average of $\sim 10 \%{ }^{2}$

The Departments of Biological Sciences, Chemistry, Earth Sciences, Physics \& Astronomy, Mathematics and Kinesiology comprise the WiSE-eligible areas of the USC College of Letters, Arts and Sciences. In 2000, there were 12 women T/TT faculty members in these departments. Since the inception of WiSE, 13 new faculty were hired in College, 10 of which joined the department of Biological Sciences, 1 in Chemistry, and 2 in Physics \& Astronomy. The high proportion of new hires in Biology are split among the 3distinct divisions: Marine Environmental Biology (3), Molecular and Computational Biology (5), and Neurobiology (2). Women now 
hold 23 of the $161 \mathrm{~T} / \mathrm{TT}$ positions in the math and science departments of the USC College, constituting $14.3 \%$.

With 22 new faculty hires under WiSE and two departures (one each in Physics \& Astronomy and Earth Sciences) since 2000, the total number of T/TT WiSE faculty at USC is now 35. Though modest by national standards ${ }^{3}$ (See Table 1, Figures 1, 2, 3 and 4), the progress made by USC in hiring and promoting women faculty is significant, relative to where it started.

With approximately 16,000 undergraduate and 15,000 graduate and professional students, USC prides itself on the diversity of its student body. In 2005, undergraduates students were $50.9 \%$ female to $49.1 \%$ male (graduate students $46.2 \%$ female to $53.8 \%$ male), $44.2 \%$ identify as nonwhite/caucasian (graduate students $42.4 \%$ ) and international students comprise $8.6 \%$ of undergraduates and $25.3 \%$ of graduate students, representing 108 countries. To better reflect the diversity of its students and to meet a standard of excellence in education that is tied to diversity, USC has embraced an aggressive faculty diversity program, influenced in part by the success of the WiSE program and augmented by the continually burgeoning activities of WiSE.

\section{Leadership and Faculty Diversity}

As outlined in the recent National Research Council report on recruiting and advancing women scientists and engineers in academia, one of the most successful strategies to recruiting and hiring women is for top administrators to publicly support the goal of advancing women in S\&E and to lead, set, and enforce policies that reflect their commitment to change. ${ }^{4}$ Nancy Hopkins' analysis of hiring strategies to achieve gender diversity at MIT confirms that when Deans and the Provost, together with knowledgeable faculty committees demonstrate a commitment to diversity and implement accountability for finding new ways to identify and hire exceptional women, significant increases in faculty diversity can occur within a short period of time. ${ }^{5}$

To meet the challenge of making USC a national leader in faculty diversity, WiSE works collaboratively with the University's academic leadership. While the permanent endowment attached to the WiSE program has made a meaningful contribution to USC's faculty diversity efforts, the essential element of its success and to its progress has been the support of top administrators. Both the Provost as well as the Deans of the USC College and the Viterbi School of Engineering share the perspective that faculty diversity is a top priority and clearly demonstrate their commitment to diversity initiatives.

In 2000 then Provost, Lloyd Armstrong, Jr., was instrumental in charging the USC faculty with the responsibility for developing the WiSE program. He established the WiSE Task Force which spent a year conceiving the initial support programs and encouraged the creative growth of the initiative. In recognition of Provost Armstrong's dedication to the objectives of WiSE, the most significant of these initial programs, the senior endowed chair, was renamed in his honor. 
Table 1: Women T/TT Faculty by Rank in Science, Math and Engineering at USC (2006)

\begin{tabular}{|c|c|c|c|c|c|c|c|c|c|c|c|c|c|}
\hline \multirow[b]{2}{*}{ Department } & \multicolumn{3}{|c|}{ Full Profesor } & \multicolumn{3}{|c|}{ Associate Professor } & \multicolumn{3}{|c|}{$\begin{array}{l}\text { Assistant } \\
\text { Professor }\end{array}$} & \multicolumn{3}{|c|}{ All Faculty } & \multirow{2}{*}{$\begin{array}{r}\text { Nat'l Avg. } \\
\%\end{array}$} \\
\hline & Total & Women & $\%$ & Total & Women & $\%$ & Total & Women & $\%$ & Total & Women & $\%$ & \\
\hline $\begin{array}{l}\text { Biological } \\
\text { Sciences }\end{array}$ & 31 & 3 & $9.6 \%$ & 12 & 4 & $33.3 \%$ & 10 & 7 & $70.0 \%$ & 53 & 14 & $26.4 \%$ & $20.2 \%$ \\
\hline Chemistry & 17 & 1 & $5.8 \%$ & 5 & 1 & $20.0 \%$ & 2 & 1 & $50.0 \%$ & 24 & 3 & $12.5 \%$ & $14.0 \%$ \\
\hline Earth Science & 17 & 1 & $5.8 \%$ & 3 & 0 & $0.0 \%$ & 1 & 0 & $0.0 \%$ & 21 & 1 & $4.7 \%$ & $13.0 \%$ \\
\hline Kinesiology & 2 & 1 & $50.0 \%$ & 3 & 1 & $33.3 \%$ & 0 & 0 & $0.0 \%$ & 5 & 2 & $40.0 \%$ & not available \\
\hline Mathematics & 26 & 1 & $3.8 \%$ & 5 & 0 & $0.0 \%$ & 1 & 0 & $0.0 \%$ & 32 & 1 & $3.1 \%$ & $8.3 \%$ \\
\hline $\begin{array}{l}\text { Physics \& } \\
\text { Astronomy }\end{array}$ & 22 & 0 & $0.0 \%$ & 3 & 1 & $33.3 \%$ & 1 & 1 & $100.0 \%$ & 26 & 2 & $7.7 \%$ & $6.6 \%(12.6 \%)$ \\
\hline $\begin{array}{l}\text { TOTAL (USC } \\
\text { COLLEGE) } \\
\end{array}$ & 115 & 7 & $6.1 \%$ & 31 & 7 & $22.6 \%$ & 15 & 9 & $60.0 \%$ & 161 & 23 & $14.3 \%$ & \\
\hline $\begin{array}{l}\text { Aerospace \& } \\
\text { Mechanical Eng. }\end{array}$ & 20 & 0 & $0.0 \%$ & 3 & 0 & $0.0 \%$ & 3 & 1 & $33.3 \%$ & 26 & 1 & $3.8 \%$ & $6.7 \%$ \\
\hline $\begin{array}{l}\text { Astronautics \& } \\
\text { Space Tech. }\end{array}$ & 2 & 0 & $0.0 \%$ & 1 & 0 & $0.0 \%$ & 0 & 0 & $0.0 \%$ & 3 & 0 & $0.0 \%$ & not available \\
\hline Biomedical Eng. & 7 & 0 & $0.0 \%$ & 1 & 0 & $0.0 \%$ & 3 & 1 & $33.3 \%$ & 11 & 1 & $9.1 \%$ & $16.0 \%$ \\
\hline $\begin{array}{l}\text { Chemical Eng. \& } \\
\text { Mat. Science } \\
\text { (incl. Petroleum) }\end{array}$ & 9 & 0 & $0.0 \%$ & 4 & 1 & $25.0 \%$ & 4 & 0 & $0.0 \%$ & 17 & 1 & $5.9 \%$ & $10.5 \%$ \\
\hline $\begin{array}{l}\text { Civil \& } \\
\text { Environmental } \\
\text { Eng. }\end{array}$ & 17 & 0 & $0.0 \%$ & 2 & 0 & $0.0 \%$ & 1 & 1 & $100.0 \%$ & 20 & 1 & $5.0 \%$ & $9.8 \%$ \\
\hline $\begin{array}{l}\text { Computer } \\
\text { Science }\end{array}$ & 14 & 1 & $7.1 \%$ & 9 & 1 & $11.1 \%$ & 3 & 2 & $66.7 \%$ & 26 & 4 & $15.4 \%$ & $10.6 \%$ \\
\hline Electrical Eng. & 44 & 2 & $4.5 \%$ & 8 & 0 & $0.0 \%$ & 7 & 0 & $0.0 \%$ & 58 & 2 & $3.4 \%$ & $6.5 \%$ \\
\hline $\begin{array}{l}\text { Industrial \& } \\
\text { Systems Eng. }\end{array}$ & 7 & 0 & $0.0 \%$ & 1 & 0 & $0.0 \%$ & 4 & 2 & $50.0 \%$ & 12 & 2 & $16.7 \%$ & $15.0 \%$ \\
\hline $\begin{array}{l}\text { TOTAL (VITERBI } \\
\text { SCHOOL) }\end{array}$ & 120 & 3 & $2.5 \%$ & 29 & 2 & $6.9 \%$ & 25 & 7 & $28.0 \%$ & 173 & 12 & $6.9 \%$ & $10.4 \%$ \\
\hline TOTAL (USC) & 235 & 10 & $4.3 \%$ & 60 & 9 & $15.3 \%$ & 40 & 16 & $40.0 \%$ & 334 & 35 & $10.5 \%$ & \\
\hline
\end{tabular}




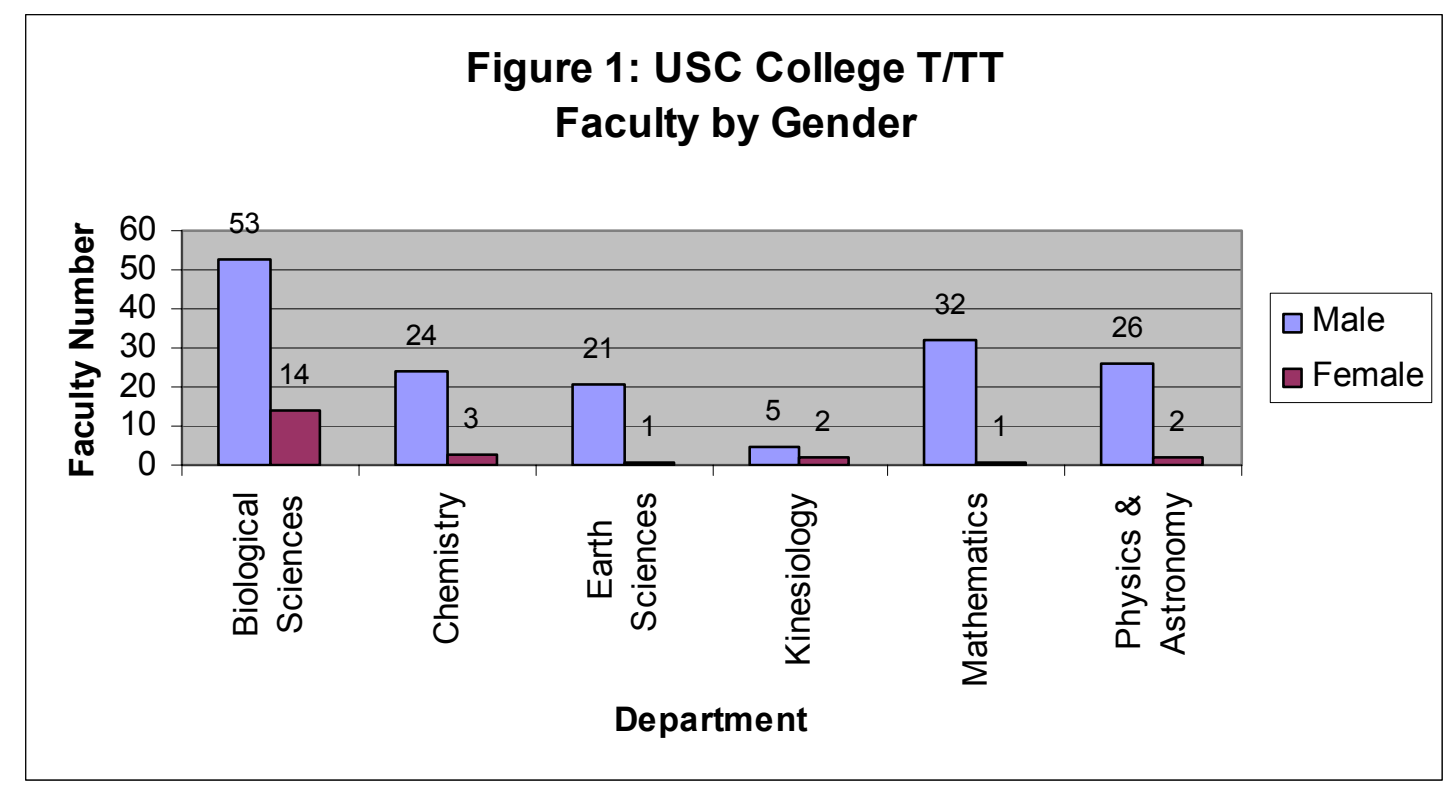

Figure 2: Viterbi School of Engineering T/TT Faculty by Gender

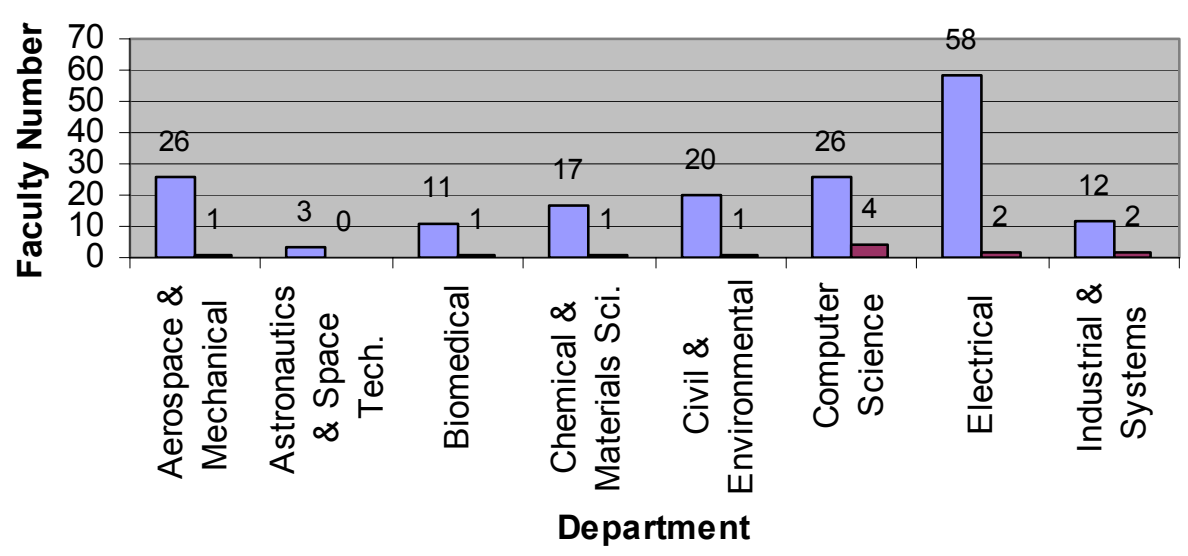




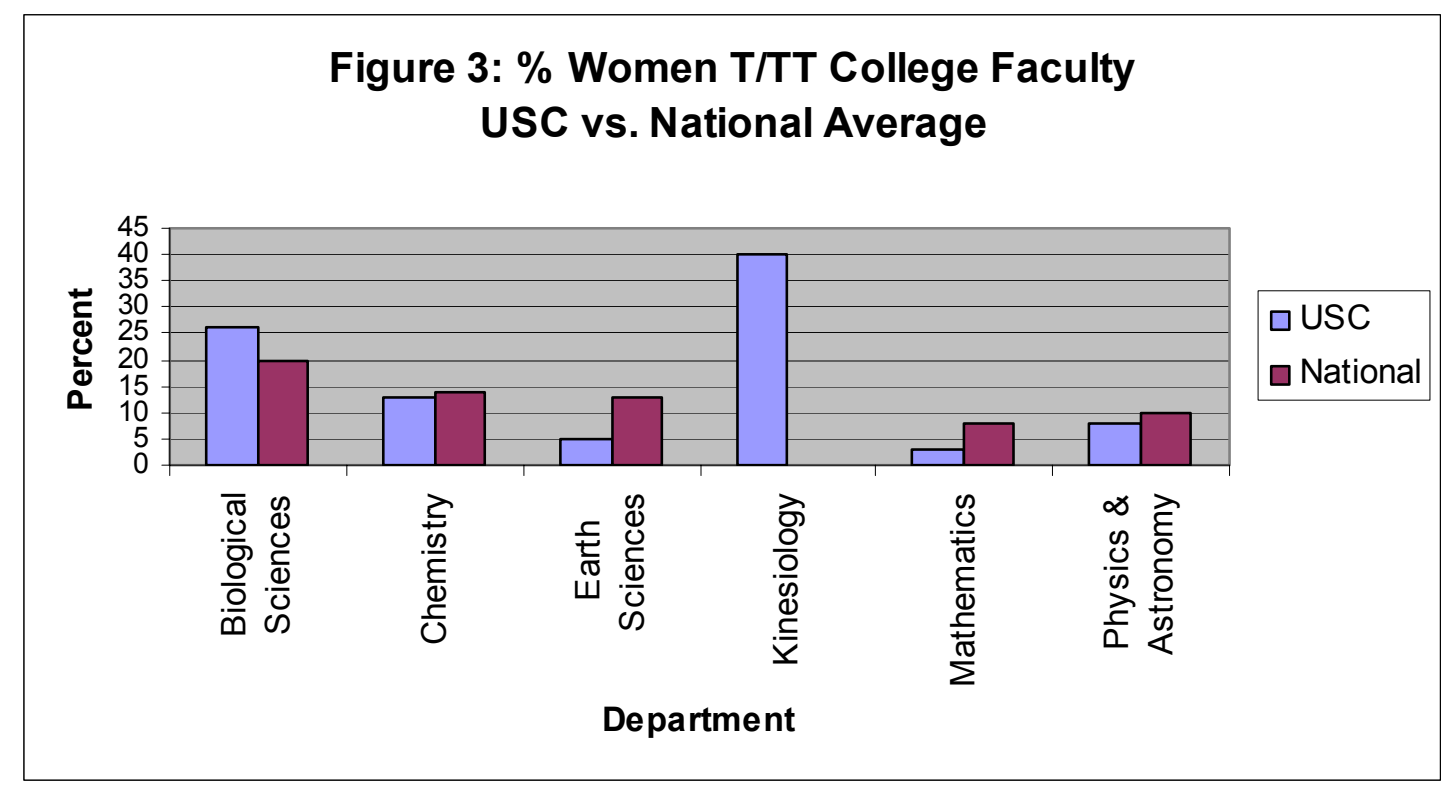

Note: National figures are not available for Kinesiology and the National Averages for Physics \& Astronomy have been combined for the sake of this comparison

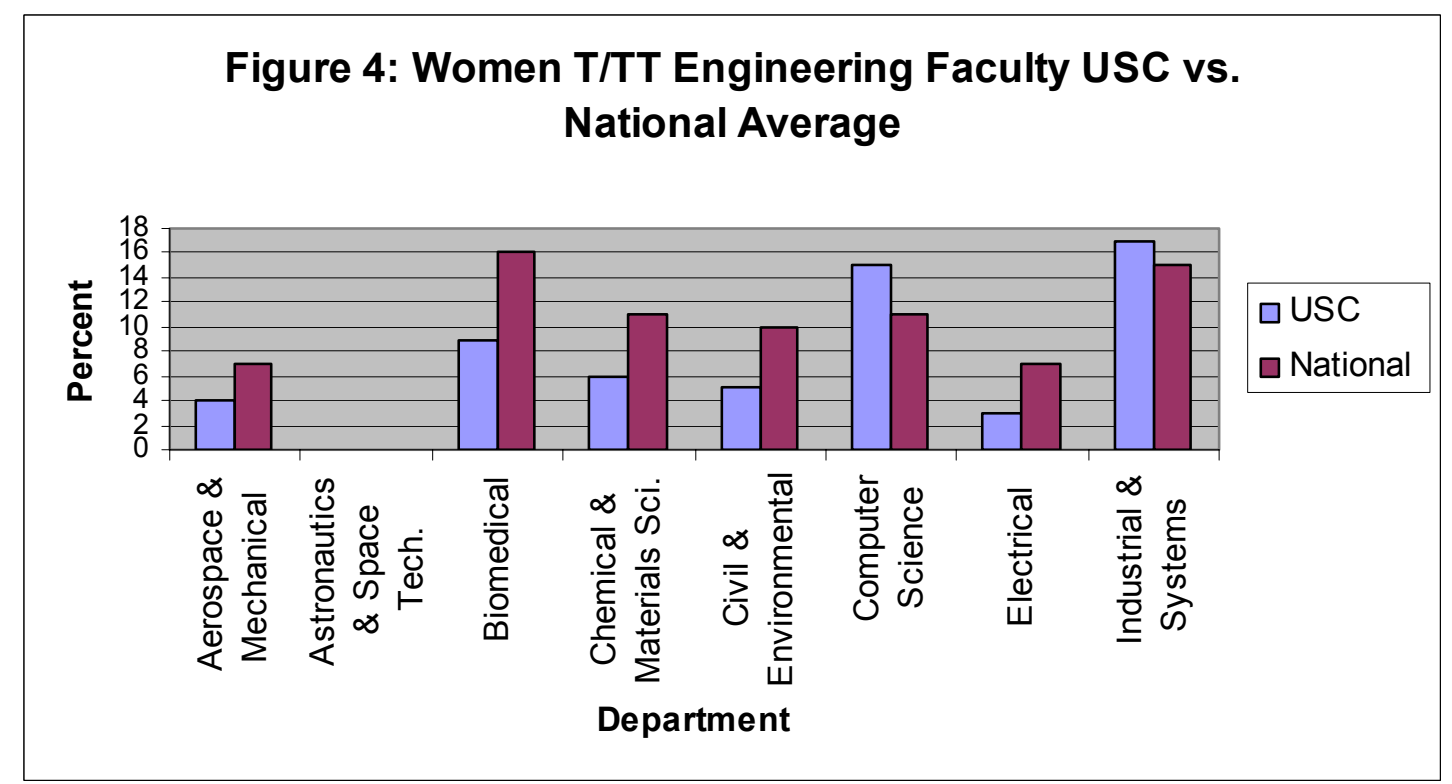

Note: National figures are not available for Astronautics \& Space Technology as a separate field, but may be included among national figures for women in Astronomy. 
When C.L. Max Nikias, Dean of the Viterbi School of Engineering from 2001-2005, assumed the role of Provost in 2005, not only did he champion the strategies and achievements of the WiSE program from his new post, but he also launched a university-wide faculty diversity hiring initiative based in part on the WiSE model. ${ }^{6}$ The significant increase in women T/TT faculty accomplished in the Viterbi School came under his leadership as Dean in cooperation with WiSE, and his support for the program has only strengthened in his role as Provost.

Upon his appointment in 2006, the Dean in the Viterbi School of Engineering, Yannis C. Yortsos, also made clear his commitment to gender diversity in outlining his vision for the direction of the School:

\footnotetext{
"The school's faculty is its foundation and its essence. Engaging and motivating all its members will be a prerequisite to any of our endeavors. Constantly improving its quality, through the recruitment of outstanding young and prominent senior faculty in key areas, and its composition, by increasing the percentage of under-represented and female faculty, should be of the highest priority."
}

With over 15 faculty hiring searches currently underway in the Viterbi School (as of Spring 2007), Yortsos instituted a strong organizational oversight mechanism to ensure that search committees are mindful of the importance of diversity and of casting a wide net in recruiting efforts. Even if a search does not yield a woman or minority hire, the system of accountability ensures that search committees are conscious of broadening their applicant pool. This form of "institutional signaling" " tangibly reinforces support for change in hiring practices at the highest levels.

Dean of the USC College of Letters, Arts and Sciences, Peter Starr, has also demonstrated his commitment to WiSE objectives by presiding over the hiring of 6 new T/TT WiSE faculty in the College in 2006 alone, including two in the Department of Physics \& Astronomy where previously there were no women T/TT faculty.

Support from USC leadership has been paramount to WiSE achieving its initial goals and to its building momentum during its first 5 years. Poised to make even more progress, WiSE entered its sixth year with unprecedented support at the highest levels for addressing the underrepresentation of women in $\mathrm{S} \& \mathrm{E}$.

\section{WiSE Programs}

Driven by the need to redress subtle biases and inequities that hinder the career advancement of women faculty, valuable input on original program design came from those affected the most by the program - senior women S\&E faculty, who formed the core of what was to become the "WiSE faculty." The WiSE faculty, as part of the formal, Provost-appointed WiSE Task Force, worked with others to survey strategies, initiatives and data to help define and refine the elements of the WiSE program.

The resulting suite of programs operate on a fundamental principle: WiSE does not pay for programs exclusively but rather matches and augments contributions by academic units. In this way, WiSE functions as a partner in helping academic units, who have already "bought in" to a hiring a faculty member, supporting a graduate student or proposing an activity, work toward 
gender equity. Moreover, by virtue of the matching principle, WiSE funds can support a much larger scope of programs than originally envisioned, create new programs, and respond to emerging needs. Descriptions for the programs follow with notation of when each was created.

\section{Faculty Programs}

1. New Faculty Recruitment (original program, 2001)

The WiSE Program provides funds to supplement and embellish offers made to new faculty in S\&E who will increase the representation of women in these fields. By providing additional funds to a new faculty member for start-up research costs, WiSE hopes to maximize the chances that such offers will be accepted. WiSE contributions to hiring packages are considered for both hiring as part of an authorized search and for target of opportunity hires. The candidate must rise to be the first choice of an open, national level search in cases of hiring as part of an authorized search, or be judged to be at the top or his/her field at his/her seniority level by both the department and the deans in the case of a target of opportunity. In both instances, the deans must provide the base salary and regular set-up funds for the faculty position.

2. Major Support for Current Faculty (original program, 2001)

Supplemental funding for major research projects through WiSE offers a way to offset barriers and life-cycle related obstacles that have been shown to slow or interrupt the careers of women faculty. Some of these barriers are subtle and can range from difficulties in meeting teaching and research demands while simultaneously raising a small child, to a reduced chance a new funding opportunities because of a lack of access to a network group. Funds may also be requested to take advantage of opportunities that arise unexpectedly and therefore are not funded through regular agencies and programs. Any USC faculty member in $\mathrm{S} \& \mathrm{E}$ is eligible to apply for up to $\$ 25,000$ in support. Successful proposals must demonstrate a strong justification for how receipt of funds will serve to increase the representation of women in $\mathrm{S} \& \mathrm{E}$.

3. Lloyd Armstrong, Jr. Endowed Chair (original program, 2001)

The Chair is awarded for a period of five years to an outstanding senior faculty member in S\&E fields who will also contribute significantly to WiSE affairs, given as part of the recruitment effort for an outstanding external candidate. The holder of the Lloyd Armstrong, Jr. Chair will be expected to contribute, for example, to the mentoring of younger female faculty. With the help of the WiSE funds, it is hoped that the WiSE activities will enhance the research program of the Chair holder. As with all WiSE support, the WiSE contribution will be used to embellish and augment offers beyond the regular set-up funds offered by the School. A minimum of $\$ 50,000 /$ year for 5 years will be allocated to the Chair holder's research fund. The endowment funds will not be used to pay regular academic-year salary. The funds can be used in ways that benefit the Chair holder, such as summer salary, housing assistance, etc.

4. Supplemental Faculty Support (original program, 2001)

Funds are available to provide supplemental research grants for tenured, tenure-track, and full-time research faculty in S\&E. Each grant will be a maximum $\$ 2,500$ annual award on a 
fiscal year basis. The faculty member must describe the purpose of the request and how receipt of supplemental funds will serve to increase the representation of women in S\&E.

5. Support for Faculty Pregnancy, Childbirth and Adoption (initiated Fall 2006)

Faculty in S\&E who have or adopt a child can face unique challenges. The existence of the WiSE Program and the networking and support that are now available to WiSE faculty at USC, present a special opportunity to address the situation and work to overcome many of the obstacles that may potentially adversely affect the careers of WiSE faculty with families. WiSE will provide guidance to help the faculty member navigate negotiations with his/her chair or dean, and may when necessary contribute to the cost of hiring a lecturer to teach the course(s) of the WiSE faculty member for the period of the agreed modified duties, and/or give priority funding through the WiSE Major Support for Faculty Program during the first two years after the birth or adoption of a child to offset grants/contracts negatively affected by childbirth or adoption.

Programs for Graduate Students and Postdoctoral Scholars

1. Postdoctoral Support (original program 2001 / terms revised in Fall 2005)

WiSE funds are available for partial salary support of a postdoctoral scholar in the amount of $\$ 25,000$ a year for a period of two years. The stipends are intended to attract outstanding postdoctoral scholars in S\&E to USC, and to prepare them for successful academic careers by providing them excellent opportunities and mentoring. Awards will be given under the condition that the total salary paid to the scholar will be at least $\$ 40,000$ and that initial support funds for the scholar are already committed by the advisor. Each year, up to two postdoctoral fellowships may be awarded in the Viterbi School of Engineering and two in the USC College. To address the opportunistic nature of postdoctoral appointments, there are two deadlines for submission each year.

2. Graduate Top-off Fellowship (original program, 2001)

This award program facilitates the recruitment of outstanding S\&E doctoral students to USC. The funds provide four incoming Ph.D. students in the USC College and four incoming $\mathrm{Ph} . D$. students in the Viterbi School of Engineering with a WiSE Fellowship to supplement their financial support packages. Each WiSE Fellowship carries a stipend of $\$ 5,000$ and may be renewed for a second year pending satisfactory progress verified by the faculty advisor. Each department in S\&E fields may nominate two candidates.

3. Merit Fellowship for Current Ph.D. Students (initiated Spring 2005) The WiSE Merit Fellowship is designed to provide advanced doctoral students with an opportunity to be recognized for their achievements. Surveys have shown that the attrition rate of female doctoral students is significantly higher that that of male doctoral students. The WiSE Program hopes this fellowship will provide support and motivation to students on an academic trajectory who demonstrate dedication to increasing the representation of women in S\&E. Two Fellowships may be awarded to Ph.D. students in the USC College and two in the Viterbi School of Engineering. Each WiSE Merit Fellowship carries a one-year stipend of $\$ 5,000$. This award is not to be used in lieu of any other funding. 
4. Travel Grants for Ph.D. Students and Postdoctoral Scholars (initiated Fall 2003) The WiSE Program provides travel grants to USC graduate students or postdoctoral fellows in $\mathrm{S} \& \mathrm{E}$ departments to attend scientific meetings in cases where either the participation by the student or the subject matter of the student's talk or poster serves to increase the representation of women in S\&E. The award provides young scholars at the beginning of their careers with opportunities for professional exposure in scientific meetings. Not only are they recognized for their research, they also have the opportunity to meet well-known scientists, other students, and successful women faculty who can serve as role models. In the case of an undergraduate student, as long as the student is a co-author of the abstract, they are also eligible to apply. WiSE provides the student or scholar with up to $\$ 300$ for travel within the State of California, $\$ 500$ for travel within the United States, and $\$ 700$ for international travel, provided their advisor makes an equal contribution of support. A total of $\$ 25,000$ in travel funds are awarded annually.

5. Fellowship to Accommodate Pregnancy, Childbirth and Adoption for Ph.D. Students and Postdoctoral Scholars (initiated Fall 2006)

One of the most important issues to increasing the representation of women in $\mathrm{S} \& \mathrm{E}$ is the balance of career and family obligations. For young scientists and engineers, this balance primarily involves childbirth, adoption, nursing and infant care. Specific to $S \& E$ is the need to avoid potentially hazardous situations during pregnancy and nursing such as exposure to chemicals, electromagnetic radiation, or other possible damaging settings. The WiSE Program developed this fellowship support program to help Ph.D. students or postdoctoral scholars and their advisors solve any conflicts that arise between the constraints of pregnancy, childbirth, adoption, nursing and infant care and the continuing work of the research program.

Doctoral students with $50 \%$ time funding may apply for a pregnancy or adoption support fellowship of up to one semester of a 50\% time university stipend at the minimum stipend rate to be used during the time of pregnancy and/or in the first year after childbirth or adoption. Postdoctoral scholars may apply to the WiSE Program for a pregnancy or adoption support fellowship in the amount of up to $50 \%$ of the 12 month salary for one semester, provided that the mentor pays the other half. The exact amount of financial support will depend upon the postdoctoral scholar's eligibility for disability benefits.

\section{Additional Programs}

1. Childcare Subsidy for Faculty, Ph.D. Students, and Postdoctoral Scholars (original program, 2001)

Supplemental Childcare Grants are available each year for any doctoral student, postdoctoral scholar or faculty member in good standing in a S\&E field who has primary childcare responsibilities for a child in the infant through pre-school age range enrolled in the USC Childcare Program. Each WiSE Childcare Grant will be paid in a monthly supplement which is equivalent to a $\$ 4,000$ subsidy over a 12 month time period and can be prorated mid-year. 
2. Undergraduate Research Fellowships (original program, 2001)

Up to fifteen fellowships are granted each year in both the USC College and in the USC

Viterbi School of Engineering to support summer and academic year research. The goal is to familiarize students with laboratory research and link them with a mentor early on. It is hoped that through the experience of first-hand research at the undergraduate level, the chances will increase that students will choose to pursue a graduate degree in science or engineering. Student recipients of the fellowship are expected to work on their research project at least 12 hours per week during the academic semester in which they receive the award $(\$ 2,500)$. For the summer, the expectation is about 300 hours or the equivalent of 8 weeks of full-time work $(\$ 4,500)$. Students must confer regularly with their faculty sponsors and, upon the sponsor's recommendation, participate in safety training, meetings, seminars, journal clubs, discussion groups, and other scholarly activities of the host laboratory, department or research group.

3. Support for Activities (informal growth over five years)

WiSE maintains discretionary funds for the support of activities that serve to increase the involvement of women in S\&E at USC. Applicants send a brief proposal outlining the scope and participants of the activity and an estimated budget. Activities may include: sponsoring a lecture, hosting a conference, attending a conference or event, or planning a field visit. For example, WiSE worked with the department of Computer Science to subsidize the attendance of six Viterbi women undergraduates at the Grace Murray Hopper Celebration of Women in Computing in October, 2006.

4. Support for Networking Groups (informal growth over five years)

Since the inception of WiSE, a networking group of T/TT WiSE faculty has assembled informally, once a month, to communicate with one another about topics of common interest, the growth and development of the USC WiSE Program, and to provide informal mentoring. These WiSE faculty monthly networking lunch meetings continue to grow in attendance and are held on the last Thursday of each month. In 2001, the invitation to attend networking meetings was extended to non-tenure-track faculty, creating a vibrant group with both common and diverse interests and experiences.

In response to a recent survey of Associate-level WiSE faculty regarding their mentoring needs and experiences conducted by the WiSE Advisory Board, respondents generally agreed that the informal mentoring provided by the WiSE faculty networking lunches is the best source of internal mentoring at USC, even when a formal system of mentoring may exist within a school or department.

Following in the model of the WiSE faculty networking group, additional affinity groups have been formed and seeded by WiSE funds. These include: Women in Chemistry, Women in Mathematics, Women in Physics, WiSE Postdoc Networking Group, and WiSE Viterbi $\mathrm{Ph} . \mathrm{D}$. Networking Group. Other recently proposed groups include a WiSE Parenting Network and Graduate Women in Biology. 


\section{Do WiSE Programs Work?}

By virtue of its ability to recruit outstanding women scientists and engineering to USC, the New Faculty Recruitment program is considered the successful and the best use of resources. More than half of the annual budget is dedicated to this program. The reason that the system for requesting WiSE funds to augment hiring offers has worked so well is because faculty candidates must meet the essential criteria of rising to top of an open, national-level search.

By rising to the top of a national-level search, the candidate is demonstrably the first choice of the department and is not selected simply to fill a perceived "woman's slot." Since WiSE funds do not go toward base salary, the school is already committed to hiring the candidate and the supplemental funds provided by WiSE enable the school to present a more attractive offer by including money to purchase equipment, hire a postdoctoral researcher, or assist with laboratory start-up costs. Moreover, the existence of WiSE and its associated support programs communicate an important message to candidates entertaining offers: that the institution is supportive of women faculty and that continued resources will be available to support WiSE faculty and their students at USC on an ongoing basis. Together, these factors contribute to a more comfortable environment for discussing issues related to the under-representation of women in S\&E and to engendering collaborative solutions.

In addition, the criteria that a candidate for any WiSE award must serve to increase the representation of women in $\mathrm{S} \& \mathrm{E}$, communicates that the candidate need not necessarily be a woman, but must meet a standard of excellence in mentoring women researchers and demonstrate success at placing them in academic positions. Meeting this threshold for support, the so-called "WiSE Justification," enables WiSE programs to be open to men and women and to eliminate any perception that access to WiSE funds are restricted by gender. This principle preserves the spirit and intent of the program to engage both men and women in addressing the problem of gender inequity in S\&E, to the benefit of all. While women are the predominate applicants to WiSE programs, men at USC have been regular recipients of WiSE funds as faculty mentors to undergraduate research fellows, graduate students, and postdoctoral scholars, as postdoctoral scholars themselves, as well as through support for partner hires, and the Major Support for Current Faculty program.

Another aspect of the success of WiSE to engender good will across disciplines, schools, and departments is the direct involvement of men and women faculty, at all career levels and from both the USC College and the Viterbi School of Engineering, in planning, evaluating, and guiding the program's development. The WiSE Advisory Board is composed of 10 members and includes research faculty, lecturers, full and associate professors, men and women. The Advisory Board meets twice each semester to review programs, progress, and investigate new program directions. Two additional committees of 3-4 members, one in each school, also with diverse faculty membership, serve as advisors on grantmaking by reviewing the applications and making recommendations for funding. The involvement of such a variety of faculty makes them stakeholders in achievement of WiSE goals and helps to create an active network of allies across campus. 
With the guidance of its diverse committees, WiSE programs have grown and evolved in response to changing needs. Continued evaluation of the success and utility of programs have helped to keep them relevant and effective.

New programs have been established. Based on the success of a similar program in the Viterbi School of Engineering providing merit-based awards to continuing Ph.D. students, the WiSE Merit Fellowship Program for Current Ph.D. students was established in 2005. Since WiSE already had the Top-off Fellowship for incoming graduate students to be used for recruitment, it was a natural step to develop a second merit-based award for continuing students to address the issue of attrition for women in S\&E graduate programs. The program is highly competitive and relies upon students' mentors and departments to nominate candidates. Recipients have expressed the desired result, that the affirmation provided by the award was a significant motivation to continuing along her career trajectory in academic S\&E.

The programs for Pregnancy, Childbirth and Adoption for Faculty, and for Ph.D. Students and Postdocs were announced in Fall 2006. To date, only one award has been granted but not yet implemented. The initial timetable for this program's implementation and evaluation is five years. Despite its early stages, through informal communication with potential applicants, the existence of the program has successfully communicated the intended message to young scientists and engineers, that the academic environment is family-friendly.

Some programs do not work as well as hoped and require modification. Childcare subsidies are not used as frequently as program designers envisioned because of the restriction of support to parents with children enrolled in the USC childcare center, where the demand for services exceeds the supply. Many students, otherwise eligible for the subsidy, cannot make use of it because of the inability for the childcare center to accommodate all who want to use the service. In order to better implement the WiSE Childcare subsidy program, steps must be taken to improve the capacity of USC childcare centers and new options for using WiSE funds to assist parents must also be explored.

In addition, the WiSE program for postdoctoral fellowships has undergone revision since its original development. In 2001, WiSE proposed to support the fellow's entire stipend. From 2002-2004, WiSE continued to offer support of the fellow's entire stipend but with the recommendation that the faculty mentor also augment the stipend from his/her own research funds. In 2005, based on the need to bring support for postdoctoral scholars in line with other WiSE Programs that require cost-sharing and the additional problem of unsuccessfully attracting outstanding applicants who were not previously affiliated with USC, the program has been modified and is being watched carefully to determine what additional changes may need to be made for the program to be effective. As of 2006, the postdoctoral fellows program now provides $\$ 25,000$ a year for two years for a fellowship and requires faculty mentors to provide additional funds to meet the minimum salary of $\$ 40,000$ per year. To encourage applicants from other institutions, they must provide three letters of recommendation of which two must be from faculty outside of USC. 


\section{WiSE Successes}

In addition to its faculty hiring initiative and formal support programs, WiSE serves as an advocate for women in S\&E at USC by participating in the development of institutional policies, creating awareness of faculty diversity issues, and in improving the institutional climate. Included among its activities toward this end are:

1. Development of a "Hiring Diversity Toolkit" and holding workshops with department chairs/search committees.

The WiSE Advisory Board developed a set of reference documents outlining best practices for search committees and strategies for identifying and attracting the best candidates beyond the traditional methods. Rather than simply distributing this "toolkit" via the website or mass distribution, WiSE leadership scheduled meetings with department chairs and search committee heads to discuss the strategies, rationale, and the support resources offered by WiSE. Moreover, the presentations conveyed a strong message of the importance of gender equity and the presence of inherent biases when evaluating candidates by both men and women. As a result of these meetings, WiSE representatives are playing a vital role in the interview process of faculty candidates, as well as assisting with the ensuing recruitment efforts. In order to sustain diversity as a priority, meetings must be held consistently and the message repeated often.

2. Assistance with Faculty Spousal Accommodation As more women select careers in academia, it is also more likely that their partners will also be academics, often in similar fields. This is especially true of women in S\&E. ${ }^{9}$ Institutions that recognize the potential competitive advantage of hiring couples will be more successful at increasing the number of women on the faculty. WiSE is playing an instrumental role in helping USC to develop creative approaches and policies to address the issue of partner hiring. ${ }^{10}$ WiSE is helping to facilitate discussions regarding partner hires, and in some cases provides funding to hire partners.

3. Hosting of lectures on WiSE-related topics

In order to increase awareness and visibility of WiSE issues, distinguished scientific speakers and contributors to WiSE issues have presented lectures on the USC campus, initiated and sponsored by the WiSE program. WiSE plans to increase the frequency of invited lecturers to at least two per semester to further raise awareness of issues of gender equity in S\&E. Visiting lecturers to date have included:

- Alice Huang, Senior Councilor for External Relations and Faculty Associate in Biology at the California Institute of Technology (2003)

- Denice Denton (deceased), former Chancellor, University of California, Santa Cruz (2004)

- Linda Buck, 2004 Nobel Laureate, HHMI, and Associate Director, Basic Sciences at the Fred Hutchinson Cancer Research Center (2005)

- Mary Ann Mason, Dean of the Graduate Division and Professor, Graduate School of Social Welfare at the University of California, Berkeley (2006) 
- Geraldine Richmond, Professor in the Department of Chemistry and Materials Science Institute at the University of Oregon (2007)

4. Building synergistic relationships with other organizations on campus to make USC a more "family friendly" institution.

WiSE is part of a larger movement at the institutional level to make academia and USC more family-friendly, in an effort to remove marriage and family as impediments to the success of women in S\&E. Toward this end, WiSE works with the USC Center for Work and Family Life, established as part of the Provost's Family-Friendly Initiative. Associated committees which include WiSE faculty, are exploring ways to enhance child care benefits and services, and to identify and evaluate the family and work related needs and concerns of faculty and staff at USC. In addition, the Academic Senate has implemented changes to extend the tenure clock to take into account work/family balance, and the Graduate School is working to institute a paid family leave policy that would accommodate pregnancy, birth, and care of a newborn or adopted child for Ph.D. students. This policy, taking effect in Spring 2007, works in collaboration with the similar WiSE program for Ph.D. students to ensure that they can balance their family responsibilities with the completion of their degree, and subsequently view academia as a viable career choice.

5. Streamlining WiSE administrative structures and processes At the time of the program's founding, the WiSE faculty wanted to ensure that all of the endowment income generated by the WiSE gift would go directly toward supporting S\&E faculty and students at USC, and that as little as possible would be absorbed by administration. Over time, as the portfolio of programs grew, the need for administrative oversight grew with it. It became clear that a formal administrative structure and process for managing the program's direction, committees, and various components was necessary. With a full-time program manager external to the $\mathrm{S} \& \mathrm{E}$ departments in place, enhancements to the WiSE website as a means of communicating with the USC community, and an online system that streamlines the process for grant application submission and review, the WiSE program is able to formally and effectively administer its programs. According to surveys of successful programs implemented from the "top down," as WiSE is from the Office of the Provost, this administrative soundness is among the most important elements to its ability to effect change. ${ }^{11}$

\section{Challenges and Future Directions}

Despite advances of women into academia in recent decades, as outlined in the recent National Academy of Science report, "Beyond Bias and Barriers," women continue to perceive a negative climate among university S\&E departments. ${ }^{12}$ Women are less satisfied in these departments due to a perceived unwelcoming atmosphere and the isolation that they frequently experience within them. WiSE faces the challenge of helping to make the climate more hospitable and accommodating, as women pioneers enter departments in S\&E at USC where few or none previously existed. 
In the most extreme cases of departmental culture, faculty members may not see the dearth of women as a problem nor do they see the necessity for striving for diversity and gender equity. Similar sentiments have been expressed recently and poignantly, in response to Evalyn Gates' argument for gender diversity in the field of physics. ${ }^{13}$ In order for a change in climate to be meaningful, individual departments must themselves identify gender inequity as a problem and take ownership of determining the solutions. One way of doing so, is for departments or schools to engage in an intensive process of self-analysis in developing a "diversity scorecard", a method successfully developed by USC Professor of Education, Estela Bensimon, to encourage institutional change. ${ }^{14}$ While a personnel- and labor-intensive process, if embraced by the leadership, WiSE can be an advocate for the implementation of such a process and in some cases may even be able to provide resources for its support. In the future, WiSE hopes to further investigate the possibility of helping to conduct a pilot gender equity scorecard project in selected S\&E departments.

Without systematic change in the structure of the academic scientific workplace, WiSE faculty face the so-called "paradox of critical mass" whereby the "minority is increasingly able to organize itself and insure its survival from within and affect a transition to an accepted presence."15 Until critical mass can be achieved, women S\&E faculty must attain strategic leadership positions wherein they can use their leadership roles to overcome resistance. Toward this end, more senior WiSE faculty have taken on roles as department chairs, deans, and vice provosts, where they can affect change. For example, at the USC Viterbi School of Engineering, a woman faculty now serves as the Senior Associate Dean of Research. However, the overwhelming number of more junior members among the WiSE faculty presents the challenge of preparing them to achieve promotion and to take on academic leadership roles.

One of the issues of particular concern to WiSE in the promotion of women faculty is excess time in rank. Since there are fewer women in senior faculty ranks across all disciplines, not just $\mathrm{S} \& \mathrm{E}$ fields ${ }^{16}$, WiSE hopes to generate greater awareness of the rate of promotion for men compared to women and the challenges (access to resources, work/family balance, and departmental climate) that may impact the slower rate for women. With the anticipated support of University administration, WiSE hopes to gain access to and analyze data that will enable a formal study of faculty promotion rates in S\&E.

As the main agent for providing networking and professional development opportunities for women S\&E faculty, WiSE faces the additional challenge of creating workshops and providing information that serve a relatively small population and yet, also meets the varying and diverse needs of the population at different career levels. While mentoring is an essential component of leadership preparedness, the few senior women who have held leadership roles available to serve in this capacity presents an additional challenge. In its goal to institute a more effective mentoring program for Assistant and Associate level faculty especially in the direction of leadership, WiSE will have to explore new and alternative means of mentoring, outside the traditional one-on-one model. 


\section{Conclusion}

The WiSE program at USC has achieved its initial goal of doubling the women T/TT S\&E faculty in its first 5 years, with the cooperation and fervent support of university leadership. Though the number of WiSE faculty is still modest by national standards, the WiSE program is exceptionally dedicated to helping those women succeed and thrive, while aggressively working toward additional recruitment and hiring. The WiSE program continues to grow in new and unforeseen ways and to nurture a network of women S\&E faculty and students who belong to a community that has a mutual stake in its ongoing success.

\footnotetext{
${ }^{1}$ Sanoff, Alvin P., At U. of Southern California, a Support Network Helps Women in Science and Engineering. Chronicle of Higher Education, 2006. 53(6):p. B8.

${ }^{2}$ American Society for Engineering Education. Databytes. ASEE Prism, 2006. 14(6).

${ }^{3}$ Nelson, Donna.J. A National Analysis of Diversity in Science and Engineering Faculties at Research Universities. 2005, Norman, OK: [online] http://cheminfo.chem.ou.edu/ djn/diversity/briefings/Diversity\%20Report\%20Final.pdf

${ }^{4}$ Committee on the Guide to Recruiting and Advancing Women Scientists and Engineers in Academia, Committee on Women in Science and Engineering, Policy and Global Affairs, National Research Council. To Recruit and Advance: Women Students and Faculty in Science and Engineering. 2006, Washington, D.C.: The National Academies Press: p. 78-79.

${ }^{5}$ Hopkins, Nancy. Diversification of a University Faculty: Observations on Hiring Women Faculty in the Schools of Science and Engineering at MIT. MIT Faculty Newsletter, 2006. 53(4): p. 22.

${ }^{6}$ Sanoff, Alvin P. A Southern Cal Program Courts Minority Professors, Chronicle of Higher Education, 2006. 53(6): p. B10.

${ }^{7}$ Yortsos, Yannis. Dean Yannis Yorsos Vision for the USC Viterbi School. 2006, Los Angeles [online] $\mathrm{http}: / /$ viterbi.usc.edu/about/vision-for-the-school.htm.

${ }^{8}$ Committee on the Guide to Recruiting and Advancing Women Scientists and Engineers in Academia, Committee on Women in Science and Engineering, Policy and Global Affairs, National Research Council. 2006, Ibid.

${ }^{9}$ According to an NSF report, women scientists are more likely than men scientists to be married to another scientist (55\% of women versus $32 \%$ of men). National Science Foundation, Women, Minorities, and Persons With Disabilities in Science and Engineering: 1996. Arlington, VA (NSF 96-311), 1996.

${ }^{10}$ Engel, Allison. Two Hires Can Be Better Than One. USC Chronicle, 2006, January 5.

${ }^{11}$ Etzkowitz, Henry, Carol Kemelgor and Brian Uzzi. Athena Unbound: The Advancement of Women in Science and Technology. 2000, Cambridge, U.K.: Cambridge University Press: p. 195-96.

${ }^{12}$ Committee on Maximizing the Potential of Women in Academic Science and Engineering, Committee on Science, Engineering and Public Policy, National Academy of Sciences. Beyond Bias and Barriers: Fulfilling the Potential of Women in Academic Science and Engineering. 2006, Washington, D.C.: The National Academies Press: p. 5-37.

${ }^{13}$ See in particular letters from Aboites and Smith, Letters, Women in Physics: Why and Why Not? Physics Today, 2006 (December): p. 10.

${ }^{14}$ Bensimon, Estela M. The Diversity Scorecard: A Learning Approach to Institutional Change. Change, 2004 (January/February).

${ }^{15}$ Etzkowitz, Henry, et.al. 2000: p.105-06

${ }^{16}$ Committee on the Guide to Recruiting and Advancing Women Scientists and Engineers in Academia, Committee on Women in Science and Engineering, Policy and Global Affairs, National Research Council. 2006, p. 86.
} 